University of Nebraska - Lincoln

DigitalCommons@University of Nebraska - Lincoln

Other Publications in Zoonotics and Wildlife

Disease

Wildlife Disease and Zoonotics

2013

\title{
Assessment of paper interstate certificates of veterinary inspection used to support disease tracing in cattle
}

\author{
Katie Portacci \\ USDA APHIS, CEAH@aphis.usda.gov \\ Ryan Miller \\ USDA APHIS \\ Philip D. Riggs \\ USDA APHIS \\ Michael G. Buhnerkempe \\ Colorado State University - Fort Collins \\ Lauren M. Abrahamsen \\ USDA APHIS
}

Follow this and additional works at: https://digitalcommons.unl.edu/zoonoticspub

Portacci, Katie; Miller, Ryan; Riggs, Philip D.; Buhnerkempe, Michael G.; and Abrahamsen, Lauren M., "Assessment of paper interstate certificates of veterinary inspection used to support disease tracing in cattle" (2013). Other Publications in Zoonotics and Wildlife Disease. 177.

https://digitalcommons.unl.edu/zoonoticspub/177

This Article is brought to you for free and open access by the Wildlife Disease and Zoonotics at DigitalCommons@University of Nebraska - Lincoln. It has been accepted for inclusion in Other Publications in Zoonotics and Wildlife Disease by an authorized administrator of DigitalCommons@University of Nebraska Lincoln. 


\title{
Assessment of paper interstate certificates of veterinary inspection used to support disease tracing in cattle
}

\author{
Katie Portacci, DVM, MPH, DACVPM; Ryan S. Miller, ms; Philip D. Riggs, PhD; \\ Michael G. Buhnerkempe, PhD; Lauren M. Abrahamsen, MEng, DVM
}

\begin{abstract}
Objective-To evaluate the differences among each state's Interstate Certificate of Veterinary Inspection (ICVI) form and the legibility of data on paper ICVIs used to support disease tracing in cattle.

Design-Descriptive retrospective cross-sectional study.

Sample-Examples of ICVIs from 50 states and 7,630 randomly sampled completed paper ICVIs for cattle from 48 states.

Procedures-Differences among paper ICVI forms from all 50 states were determined. Sixteen data elements were selected for further evaluation of their value in tracing cattle. Completed paper ICVIs for interstate cattle exports in 2009 were collected from 48 states. Each of the 16 data elements was recorded as legible, absent, or illegible on forms completed by accredited veterinarians, and results were summarized by state. Mean values for legibility at the state level were used to estimate legibility of data at the national level.

Results_-ICVIs were inconsistent among states in regard to data elements requested and availability of legible records. A mean \pm SD of $70.0 \pm 22.1 \%$ of ICVIs in each state had legible origin address information. Legible destination address information was less common, with $55.0 \pm 21.4 \%$ of records complete. Incomplete address information was most often a result of the field having been left blank. Official animal identification was present on $33.1 \%$ of ICVIs.

Conclusions and Clinical Relevance-The inconsistency among state ICVI forms and quality of information provided on paper ICVIs could lead to delays and the need for additional resources to trace cattle, which could result in continued spread of disease. Standardized ICVIs among states and more thorough recording of information by accredited veterinarians or expanded usage of electronic ICVIs could enhance traceability of cattle during an outbreak. (J Am Vet Med Assoc 2013;243:555-560)
\end{abstract}

$T^{\prime}$ he occurrence of an animal disease listed by the World Organisation for Animal Health could have severe consequences for exports of cattle and beef products as well as domestic production. The cattle industry in the United States comprises approximately 93 million cattle, with an estimated 22 million moving among states annually. ${ }^{1}$ In 2010, the value of US beef export products was estimated at $\$ 3.8$ billion and live cattle exports were valued at $\$ 132$ million. The identification of bovine spongiform encephalopathy in the United States in 2003 highlighted the need for a comprehensive traceability system. ${ }^{2}$ A period $>50$ months was required for the United States to regain its export market. ${ }^{3}$ The movement of cattle throughout the United States is driven by cost, availability of feed, and industry infrastructure. ${ }^{1}$ The present infrastructure is not designed to trace individual animals throughout the course of their life, and trace investigation periods for endemic diseases can exceed 150 days. $^{4}$

From USDA APHIS Veterinary Services (Portacci, Miller, Riggs, Abrahamsen), Fort Collins, CO 80526; and Department of Biology, College of Natural Sciences, Colorado State University, Fort Collins, CO 80526 (Buhnerkempe).

Supported by USDA cooperative agreements 11-9208-0269-CA and 09-9208-0235-CA.

The authors thank Dr. Colleen Webb for technical assistance.

Address correspondence to Dr. Portacci (katie.portacci@aphis.usda. gov).

\section{Abbreviation \\ ICVI Interstate Certificate of Veterinary Inspection}

The ability to trace animals is a critical component in livestock disease control and eradication efforts. The availability of records documenting individual animals as they move through the system can help identify the source of infection. Rapidly tracing the source herd and exposed animals during an outbreak situation maximizes the effectiveness of emergency response actions and minimizes the social, economic, and environmental costs. ${ }^{5-7}$ Animal health authorities in the United States have proposed new animal disease traceability program requirements for the interstate movement of farm-raised livestock and poultry to ensure infected and exposed animals can be quickly traced during an outbreak. According to the current traceability plan, cattle are a priority in this effort because of the gaps in individual animal identification and movement documentation, compared with other livestock industries. ${ }^{4}$

Tracing animal movements begins with the detection of an infected animal or herd and has the goal of identifying all animals that may have been exposed prior to (trace-in) and after (trace-out) the infected animal enters a herd. The ability to trace individual 
animals relies on individual identification, the ability to track movements, proper identification of premises, and recording of this information. ${ }^{8}$ The ICVI is an important tool to assist with tracing the movement of animals among states. An ICVI is an official document that may be signed by an accredited veterinarian or an official state or federal veterinarian. The ICVIs are often referred to as health certificates; however, this is misleading because an ICVI only requires a veterinarian to certify that an animal or group of animals is apparently healthy with no visible signs of communicable diseases at the time of inspection. It does not certify that the animal is free of all infectious diseases. In general, ICVIs are required for interstate cattle movement with the exception of animals going directly to slaughter. The ICVIs are also used for intrastate movement when required for exhibition or other purposes. Although ICVIs do not confirm that interstate movements of livestock occurred (ie, an ICVI can be issued but the shipment may not occur), in many instances, it provides the only source of information to help establish where animals moved to and from across state lines. If the previous location of an infected animal is identified, other exposed animals at the same location could be tested.

The present traceability system relies on accredited veterinarians to provide accurate information on an ICVI to trace animal movement and identify exposed animals. The process for use of ICVIs requires the accredited veterinarian to inspect the animals being shipped, fill out the ICVI required by the state of origin, and provide a copy to the originating state, destination state, and owner. With the exception of exhibition animals in some states, cattle must be moved within 30 days after certification, after which time the ICVI expires (60 days in 1 state). Accredited veterinarians have 2 options when filling out an ICVI: use of paper or electronic forms. Multiple electronic repositories exist for submitting ICVIs, but for cattle shipments, these are used by only a small percentage of accredited veterinarians. Most accredited veterinarians use paper ICVIs for cattle that are shipped across state lines.

The objective of the study reported here was to evaluate differences in data elements requested on paper ICVI forms by state and the legibility of the data provided by accredited veterinarians to support animal disease tracing in cattle. This assessment was intended to provide an understanding of the data presently available and the value of paper ICVIs for tracing cattle movements. A more thorough understanding of the available data will provide a foundation for further enhancement of the use of paper ICVIs in existing animal tracing systems or promote expanded usage of electronic systems.

\section{Materials and Methods}

ICVI form review-To describe the differences in paper ICVIs among the 50 states, each state provided an example of their paper ICVI form. Data elements listed on each state's ICVI were recorded in an electronic database for comparison of the similarities and differences. This initial comparison identified 16 data elements that were similar among states and have the potential to contrib- ute to efficient individual animal tracing. These data elements included 4 elements of the origin (premises identification, address, city, and state), 4 elements of the destination (premises identification, address, city, and state), 3 elements of the date (dates of issue, shipment, and examination), and 5 elements of individual animal identification (primary and secondary identification, breed, age, and sex). The primary and secondary identification fields were recorded as either official animal identification or unofficial animal identification, depending on the information contained in the field. Official animal identification was defined as official brucellosis vaccination ear tags, National Uniform Eartagging System (so-called silver or Brite tags), or animal identification numbers (also called 840 tags). ${ }^{9}$ Unofficial identification included any alternate identification such as an animal name or management tags. Of these 16 elements, 3 (origin address, destination address, and official identification) were considered the most effective for tracing an individual animal during an outbreak investigation. The remaining 13 elements were considered useful in the absence of the 3 elements.

Legibility-To assess the availability of legible data in the 16 data elements, when filled out by accredited veterinarians, states were asked to provide at minimum a $10 \%$ systematic sample (ie, every tenth cattle ICVI) of completed ICVIs for cattle leaving the state in 2009, although some states did provide all of their 2009 export ICVIs. A systematic sample of every tenth cattle ICVI was used because of a lack of information on the total number of cattle export ICVIs for each state in 2009, which has since been estimated to be approximately 200,000 ICVIs. Because of the large number of ICVIs received, state-stratified subsamples were necessary to estimate the variability in the legibility of data on ICVIs from each state. The subsample size needed from each state was calculated by means of a power analysis based on estimates of the percentage of ICVIs that contained a proxy for individual animal identification information (ie, if the ICVI listed age, breed, and sex of the animals) obtained from a separate ongoing study of the shipment characteristics of ICVIs. Specifically, the state subsample was the lesser of either $5 \%$ of a state's ICVIs as determined from the sample provided or the sample size needed to achieve a high power (ie, 0.9) for a Fisher exact test measuring the difference between the percentage of ICVIs from the state that contained the proxy for individual animal identification and the nationwide percentage of ICVIs containing the same information.

Data analysis - The 16 data elements important for accurate tracing of individual animals were classified as legible, illegible, or blank (no data) by examination of the information provided by the accredited veterinarian who filled out the form. Each of the 16 data elements was summarized by the percentage of forms with legible data, by state. Data elements that were blank or illegible were deemed unusable for tracing. This statelevel information was used to summarize the availability of legible data at the national level. States that did not request a particular data element were excluded from the national estimates for that element. Mean \pm 
SD values determined across states were used to estimate legibility at the national level.

\section{Results}

Comparison of state ICVIs-The data elements requested on a paper ICVI varied among the states. ${ }^{a}$ No definitions were provided for any of the terms on any of the ICVIs. The origin and destination information requested was not standardized. Some states requested the physical address of the animals, some requested the mailing address of the owner or consignor, and some did not differentiate among the types of addresses. Forty-eight (96\%) states had a specific location on the ICVI for the consigner or owner address, and 46 (92\%) had a location on the ICVI for the consignee or receiver address. Eighteen (36\%) states also specifically requested the physical address from which the animals originated.

All states requested at least 1 date on the ICVI, although it was sometimes unclear exactly what that date referred to. Fourteen (28\%) states had a space for a shipping date, $30(60 \%)$ had a place for an issue date, and $40(80 \%)$ either requested an examination date or only had a date line next to the accredited veterinarian's signature line. Many states requested some combination of the 3 dates.

Forty-nine (98\%) states requested the species of animal to be identified. All 50 states requested the age, sex, and breed of the animal. Thirty-three states requested purpose of shipment, and in total, 23 choices for those purposes were listed among the 33 states. ${ }^{b}$ Forty-three (86\%) states had a space for brucellosis vaccine tattoo, and 49 (98\%) had a space on the form for a primary identification.

The accredited veterinarian's signature was requested by 49 (98\%) states; however, only 37 (74\%) states requested that veterinarians also print their name. States requested a variety of disease-related information, with results of testing for the causative organisms of bovine tuberculosis (47 states) and brucellosis (46 states) most commonly requested.
Presence of legible ICVI data-All 50 states were also asked to provide a random sample of their completed interstate export records for cattle in 2009. Forty-nine of 50 (98\%) states agreed to participate in this part of the study. Of the participating states, Alaska did not have any interstate export records that met the study criteria, resulting in 7,630 ICVIs available for evaluation from 48 states. Each state was ranked according to the proportion of ICVIs with legible data present in each of 3 elements considered key for tracing purposes: origin address, destination address, and offcial animal identification. The states that performed the best for origin address were Maine, Connecticut, and Delaware $(100 \%)$; the state that performed the best for destination address was Idaho (91.7\%), and the state that performed the best for official identification was New York (84.9\%).

Location information (origin and destination) was frequently recorded on ICVIs. A mean \pm SD of $70.0 \pm 22.1$ ICVIs in each state had legible origin address (street level) information. The percentage of forms with legible origin address information was variable, ranging from $21.1 \%$ to $100.0 \%$ across the 48 states that requested it (Table 1). Of the records with unusable origin address information, $65 \%$ were left blank, $2 \%$ were illegible, and 33\% used a post office box address rather than a street address. Legible destination address information was less common, with a mean \pm SD of $55.0 \pm 21.4 \%$ of ICVIs with legible records (range, $10.0 \%$ to $91.7 \%$ ). The most common finding for unusable destination address information was a blank field (85.6\% of unusable records). City information was commonly recorded for origin $(99.1 \pm 2.0 \%)$ and destination $(97.3 \pm 9.3 \%)$ of the shipment.

Information related to dates on an ICVI (issue, shipment, and examination) was highly variable. When specifically requested, issue date and shipping date were the most commonly recorded dates $(98.0 \pm 7.1 \%$ and $91.2 \pm 17.8 \%$ of ICVIs, respectively). Examination date was the least commonly recorded date $(39.9 \pm$ $25.9 \%$ of ICVIs).

The most frequently recorded information was related to sex $(97.4 \pm 4.4 \%$ of ICVIs), cattle breed (86.5

Table 1-Percentages of ICVI forms in each state for which information recorded for 16 data elements was legible.

\begin{tabular}{|c|c|c|c|}
\hline Data element & No. of states* & Mean \pm SD (\%) & Median (range [\%]) \\
\hline \multicolumn{4}{|l|}{ Origin } \\
\hline Premises identification No. & 18 & $8.0 \pm 14.2$ & $2.0(0.0-60.8)$ \\
\hline Address & 48 & $70.0 \pm 22.1$ & $71.4(21.2-100.0)$ \\
\hline City & 48 & $99.1 \pm 2.0$ & $100.0(90.0-100.0)$ \\
\hline State & 48 & $99.0 \pm 2.1$ & $100.0(90.0-100.0)$ \\
\hline \multicolumn{4}{|l|}{ Destination } \\
\hline Premises identification No. & 16 & $0.2 \pm 0.4$ & $0.0(0.0-1.3)$ \\
\hline Address & 48 & $55.0 \pm 21.4$ & $53.2(10.0-91.7)$ \\
\hline City & 48 & $97.3 \pm 9.3$ & $100.0(40.0-100.0)$ \\
\hline State & 48 & $98.8 \pm 4.0$ & $100.0(100.0-100.0)$ \\
\hline \multicolumn{4}{|l|}{ Date } \\
\hline Issue & 30 & $98.0 \pm 7.1$ & $100.0(60.8-100.0)$ \\
\hline Shipping & 15 & $91.2 \pm 17.8$ & $99.1(37.5-100.0)$ \\
\hline Examination & 40 & $39.9 \pm 25.9$ & $33.0(5.1-100.0)$ \\
\hline \multicolumn{4}{|l|}{ Animal information } \\
\hline Official identification No. & 48 & $33.1 \pm 25.1$ & $25.4(0.0-84.9)$ \\
\hline Unofficial identification No. & 48 & $54.0 \pm 23.1$ & $54.1(7.4-100.0)$ \\
\hline Breed & 48 & $86.5 \pm 18.7$ & $94.7(33.3-100.0)$ \\
\hline Age & 48 & $82.8 \pm 16.3$ & $89.2(46.6-100.0)$ \\
\hline Sex & 48 & $97.4 \pm 4.4$ & $99.3(82.7-100.0)$ \\
\hline
\end{tabular}


$\pm 18.7 \%)$, and age $(82.8 \pm 16.3 \%)$. The most frequent reason for unusable data related to sex, cattle breed, and age was leaving the field blank $(97.2 \%, 96.9 \%$, and $77.5 \%$, respectively, of the unusable records). Official animal identification was present on only $33.1 \pm 25.1 \%$ of ICVIs and ranged from $0.0 \%$ to $84.9 \%$ in the 48 states that requested identification on an ICVI. When official animal identification information was unusable, the space provided was left blank (99.5\%). Unofficial animal identification was more common, with a mean of $54.0 \pm 23.1 \%$ of ICVIs in each state recording some form of unofficial individual animal identification (range, $7.4 \%$ to $100.0 \%$ ).

\section{Discussion}

Incursion of a contagious or World Organisation for Animal Health-listed disease can be costly to livestock industries because of the loss of animals, trade restrictions, and loss of consumer confidence. ${ }^{10-12}$ Outbreaks of highly infectious diseases have resulted in large-scale social and economic devastation. ${ }^{13,14}$ The United States has been successful in avoiding largescale outbreaks of highly infectious diseases in cattle but continues to manage sporadic occurrences of bovine brucellosis, tuberculosis, and other endemic diseases. Presently, the period required for completion of trace investigations for bovine tuberculosis may exceed 150 days, with additional time spent testing unexposed cattle because of lack of available individual animal identification. ${ }^{4}$ The 2003 bovine spongiform encephalopathy case exemplified the importance of tracing an individual animal throughout its life to US livestock markets. ${ }^{2}$ Rapidly detecting and tracing infected animals in a highly infectious disease outbreak are critical to minimizing the impact of the outbreak by reducing the number of animals euthanized and other costs. ${ }^{15-18}$ By enhancing the ability to trace individual animals, the cost of managing diseases endemic to the United States could also be reduced and improve the marketability of US products in countries where traceability yields a price premium. ${ }^{18}$

An effective animal traceability system requires common standards for collecting information, presence of legible information, and the ability to rapidly recall this information when necessary. ${ }^{19}$ Efforts have been underway in the United States to develop a traceability system that is cost-effective for producers yet provides animal health officials the information necessary to respond to disease situations. Concerns over confidentiality, liability, and cost create challenges for implementing mandatory animal identification and the use of electronic systems. The USDA's new traceability program encourages the use of low-cost technology and allows states the opportunity to develop a system that works for them. ${ }^{4}$ With the limited use of electronic systems for cattle, the paper ICVI remains an important component of a state's traceability program and provides information that all states have access to for tracing animals during an outbreak.

Limitations of the usefulness of paper ICVIs as they presently exist must be understood as states continue developing their own traceability systems. Each state has its own unique ICVI (or multiple ICVIs, in some states) designed to satisfy state and federal requirements. Because each state's form contains different information in different locations, tracing shipments of animals that entered a state or verifying that all import requirements have been met may take additional time for importing states. Accredited veterinarians certify a single shipment through an ICVI, but that record could have far-reaching implications in the event of an outbreak. The incompleteness of information often provided by accredited veterinarians creates an added barrier to the effective use of paper ICVIs to trace cattle.

Although all 50 states request certain elements on an ICVI, results of this study indicated that many elements do not have definitions or are missing useable information when completed by accredited veterinarians. Because the critical elements are not always complete and legible, all of the elements indicated (Table 1) should be included on a uniform ICVI, with the exception of a standardized date field. Although address information is requested by all 50 states, failure to differentiate between physical locations of the owner or animal, mailing addresses, and markets will delay completion and affect the accuracy of animal tracing. The address of the owner may be helpful, but it does not identify the location of the animals, which is necessary to help identify exposed animals. Seventy percent of origin address information provided by accredited veterinarians (to the street level) was legible, but only $55 \%$ of the destination addresses were legible. The unusable data were most commonly caused by leaving the field blank. However, a post office box address was also used on some ICVIs but does not represent an animal's location. Thus, ICVIs cannot always be relied on for rapid tracing of either individual animals or shipments of animals to a physical location where other animals may be exposed. When other elements (eg, identification, age, breed, and purpose) are available to help identify an animal, tracing only to the city or state scale will hinder an investigation. Age, breed, and sex information are standard elements on all ICVIs, but the purpose of shipment differs among all states. Standardizing the purposes of shipment among states would make the information more helpful for prioritizing traces, such as tracing breeding animals before tracing animals directed to slaughter channels, when appropriate.

Differences in the manner in which dates are requested may also hinder an investigation by leading to confusion regarding when the animals were actually shipped versus when they were examined by the accredited veterinarians. Only 15 states requested a shipment date, but it was provided on $91.2 \%$ of IVCIs, indicating veterinarians often have an idea of when a shipment is intended to occur. Although a shipping date may not always be exact, it may provide a narrower window when searching for exposed animals. With only an issue date or examination date, the animal may be moved at any time within 30 days (60 days in 1 state) after the ICVI is written. The lack of a specific date could complicate searching for animals exposed to an infectious disease at locations such as markets. For example, when all animals passing through markets for a period of 30 days need to be tested because the exact date an infected ani- 
mal passed through is unknown, animals that were not exposed would undergo unnecessary testing. This will cost additional time and resources for animal health officials as well as producers.

Individual animal identification is a key component in the rapid response to disease outbreaks in cattle. ${ }^{19-21}$ The time required to trace back an individual animal is greatly extended as the percentage of unidentified animals increases. ${ }^{4}$ In the United States, it has been estimated that at least $70 \%$ of the animals in a specific species sector (eg, beef cattle) must be identified and traceable to effectively respond to an outbreak situation..$^{22}$ According to the National Animal Health Monitoring System 2007-2008 beef study, approximately two-thirds of beef cow-calf producers used at least 1 form of individual identification for cows and almost half of all operations used individual identification for heifers. Nearly $65 \%$ of the cows and calves had some form of individual identification, and approximately $75 \%$ of feedlot and stocker cattle were unofficially identified. ${ }^{23}$ According to the National Animal Health Monitoring System 2007 dairy study, ${ }^{24}$ 93\% of operations and $97.4 \%$ of cows had some form of individual animal identification. In the present study, 49 states had a space for a primary animal identification on the ICVI; however, this identification could be an official animal identification or an unofficial identification. Without definitions, this field may contain animal names or other identifiers that are not unique to the animal. Official animal identification was available on $33.1 \%$ of completed records, and $54.0 \%$ contained an unofficial identification. It was not apparent whether animal identification was missing on these ICVIs because the accredited veterinarian did not fill out the information or the animal was not uniquely identified. According to the USDA's proposed rule, cattle moving interstate would be accompanied by an ICVI and officially identified (with some exceptions). ${ }^{4}$ However, in 2009, when these ICVIs were written, the National Animal Identification System, a voluntary program, was still in development and being met with resistance from producer groups. ${ }^{25}$ Only $18 \%$ of cattle premises were registered in the electronic premises identification system maintained by the USDA at that time. ${ }^{25}$

To improve the use of paper ICVIs by states, enforcement of legible and complete information by accredited veterinarians is essential. Unfortunately, accredited veterinarians do not always print their name or provide their national accreditation or state license number; therefore, it may be difficult for states to identify veterinarians that routinely fill out paper ICVIs incorrectly. Additional work is needed to determine why more paper ICVIs are complete and legible in some states, compared with others. Regional differences, production types, frequency of filling out ICVIs, and the ratio of veterinarians to farms may influence the quality of information provided on an ICVI. The National Veterinary Accreditation Program presently has a training module for accredited veterinarians on how to fill out an ICVI, which, along with other training methods, may help states improve the quality of their paper ICVIs.

Methods for rapidly retrieving information from paper ICVIs may also help states to use paper records more effectively. Presently, there is no consistent manner by which all states file paper records for animals entering their state (eg, by state or by date of receipt), which may create delays in retrieving the ICVI of concern. Many state officials have discussed retrospectively entering paper records into an electronic database for shipments into their state, but this is challenging when each state's paper ICVI collects different data and the data are often illegible.

The increased usage of existing electronic systems by accredited veterinarians would improve the usefulness of ICVIs. Electronic record keeping is required in many European countries to assist with animal tracing. Electronic ICVIs would provide a single format for all 50 states and require specific information to be entered in a number of fields, including a legible origin and destination address. These critical data fields must be completed, or the record cannot be submitted. Electronic ICVIs would also prevent the problem of poor legibility and provide immediate access to state officials in an outbreak. An unpublished assessment of an electronic database of ICVIs (Veterinary Services Process Streamlining) maintained by the USDA evaluated how well electronic ICVIs represented cattle movement in the United States and found that, in 2009, they represented an estimated $1.4 \%$ of cattle shipments and were highly biased toward shipments originating in or destined for Texas and Wisconsin. Thus, presently, electronic ICVIs represent a small, unrepresentative sample of cattle movements, which limits their general use in traceability and studies of disease spread. However, the quality of these electronic records appears to be superior to paper ICVIs.

The value of the paper ICVI for tracing individual animals may be limited, but it remains the 1 document all states can use to track the interstate movements of cattle. In the absence of electronic ICVIs, a uniform paper ICVI used by all states (or at least consistency in standard fields with appropriate definitions) and enforcement of legibility would enhance the use of paper ICVIs and ensure that the most critical elements (origin address, destination address, and individual animal identification) are always provided.

\footnotetext{
a. A complete list of all elements requested on an ICVI and the differences among states is available from the corresponding author.

b. A complete list of all purposes of shipment requested and number of states requesting is available from the corresponding author.
}

\section{References}

1. Shields D, Mathews K. Interstate livestock movements. Electronic outlook report from the Economic Research Service. Washington, DC: USDA Economic Research Service, 2003.

2. Bailey D, Slade J. Factors influencing support for a national animal identification system for cattle in the United States. Available at: ageconsearch.umn.edu/bitstream/20293/1/sp04ba08. pdf. Accessed Nov 5, 1012.

3. Johnson K, Stone K. Export market recovery post livestock disease outbreak—cattle. Fact sheet: data, information \& economic analysis. Denver: Livestock Marketing Information Center, 2011.

4. USDA APHIS. Traceability for livestock moving interstate. Fed Regist 2011;72:50081-50110.

5. Elbers AR, Moser H, Ekker HM, et al. Tracing systems used during the epidemic of classical swine fever in The Netherlands, 1997-1998. Rev Sci Tech 2001;20:614-629.

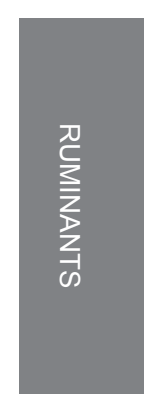


6. Jones JPH, Carlberg J, Pendell DL. Effects of a traceability system on the economic impacts of a foot-and-mouth disease outbreak. Available at: ageconsearch.umn.edu/bitstream/ 98781/2/Carlberg\%20SAEA\%202011\%20Selected\%20Paper. pdf. Accessed Nov 5, 2012.

7. Saatkamp HW, Dijkhuizen AA, Geers R, et al. Economic evaluation of national identification and recording systems for pigs in Belgium. Prev Vet Med 1997;30:121-135.

8. Vallett B. Animal identification and product traceability from the farm to the fork must be progressively implemented worldwide. Available at: www.oie.int/for-the-media/editorials/detail/ article/animal-identification-and-product-traceability-from-thefarm-to-the-fork-must-be-progressively-imple/. Accessed Jan 7, 2013.

9. USDA APHIS. Animal disease traceability framework: official eartags - criteria and options, 2011. Available at: www.aphis. usda.gov/traceability/downloads/eartag_listing.pdf. Accessed Jan 7, 2013.

10. Paarlberg P, Hillberg Seitzinger A, Lee J, et al. Economic impacts of foreign animal diseases. Washington, DC: USDA Economic Research Service, 2008.

11. Krystynak RHE, Charlebois PA. The potential economic impact of an outbreak of foot-and-mouth disease in Canada. Can Vet J 1987;28:523-527.

12. Jin HJ, Skripnitchenko A, Koo WW. The effects of the BSE outbreak in the United States on the beef and cattle industry. Fargo, ND: North Dakota State University Center for Agricultural Policy and Trade, 2004.

13. Yang PC, Chu RM, Chung WB, et al. Epidemiological characteristics and financial costs of the 1997 foot-and-mouth disease epidemic in Taiwan. Vet Rec 1999;145:731-734.

14. Thompson D, Muriel P, Russell D, et al. Economic costs of the foot-and-mouth disease outbreak in the United Kingdom in 2001. Rev Sci Tech 2002;21:675-687.

15. Carpenter TE, O'Brien JM, Hagerman AD, et al. Epidemic and economic impacts of delayed detection of foot-and-mouth dis- ease: a case study of a simulated outbreak in California. J Vet Diagn Invest 2011;23:26-33.

16. Elbakidze L, Highfield L, Ward M, et al. Economics analysis of mitigation strategies for FMD introduction in highly concentrated animal feeding regions. Appl Econ Perspect Pol 2009;31:931-950.

17. Hagerman A, Looney JC, McCarl BA, et al. Rapid effective traceback capability value in reducing the cost of a foot-and-mouth disease event. Available at: agecom2.tamu.edu/people/faculty/ mccarl-bruce/papters/1803Rapid_Effective_Trace.pdf. Accessed Nov 5, 2012.

18. McGrann J, Wiseman H. Animal traceability across national frontiers in the European Union. Rev Sci Tech 2001;20:406-412.

19. Stanford K, Stitt J, Kellanr JA, et al. Traceability in cattle and small ruminants in Canada. Rev Sci Tech 2001;20:510522.

20. Disney WT, Green JW, Forsythe KW, et al. Benefit-cost analysis of animal identification for disease prevention and control. Rev Sci Tech 2001;20:385-405.

21. Keeling MJ, Danon L, Vernon MC, et al. Individual identity and movement of networks for disease metapopulations. Proc Natl Acad Sci U S A 2010;107:8866-8870.

22. USDA APHIS. A business plan to advance animal disease traceability. National Animal Identification System business plan. Version 1.0. Washington, DC: USDA, 2008.

23. USDA APHIS Veterinary Services. Part 1: reference of 1997 beef cow-calf management practices. Washington, DC: Centers for Epidemiology and Animal Health: National Animal Health Monitoring Systems, USDA, 1997.

24. USDA APHIS Veterinary Services. Dairy cattle identification practices in the United States, 2007. Washington, DC: Centers for Epidemiology and Animal Health: National Animal Health Monitoring Systems, USDA, 2007.

25. Greene J. Animal identification and traceability: overview and issues. Washington, DC: USDA, Congressional Research Service, 2010;R40832. 